\title{
A SOLAR TIMBER-DRYER EQUIPPED WITH AN AIR COLLECTOR
}

A generally well-known high energy requirement for technological processes of timber drying and the fact that the world's supply of the conventional energy sources has considerably decreased are the decisive factors forcing us to look for some new, if possible, renewable energy sources for this process emphasising their environmental reliability.

One of the possibilities of how to replace, at least partly, the conventional energy sources - heat in a drying process is solar energy.

Air-drying of timber usually has a series of disadvantages such as time expenditure, drying defects in the wood and inadequate final moisture content. To avoid these drawbacks, kiln drying is used in many cases to dry the timber, but this involves higher investments for equipment and greater operating costs. The energy used to dry timber is approximately 60 to $70 \%$ of the total energy used to manufacture timber.

A method that obviates or reduces the disadvantages of air-drying and, at the same time, reduces the costs of kiln drying, is drying with solar heat. For the most part, fossil fuels are currently used to dry timber products. Solar energy can replace a large part of this depletable energy since solar energy can supply heat at the temperatures most often used to dry wood (i.e. from 40 to $100{ }^{\circ} \mathrm{C}$ ). Solar timber-dryers offer an attractive solution.

Key words: solar timber-dryer, energy savings, solar air collector, drying defects, drying quality

\section{Introduction}

The Slovak Republic (the SR) similarly as other countries with the well-developed industry including wood processing industry can easily spend five or more per cent of its national energy consumption on drying processes. Wood drying, as with other goods drying, requires a large quantity of energy.

\section{Wood-processing industry}

The tree-covered area of the Slovakian forestland represents $19,258 \mathrm{~km}^{2}$. Primary forest resources for timber production represent a substantial wood potential. It is considered that woodcutting for industrial use is at the level of $5 \mathrm{mil} . \mathrm{m}^{3}$ p.a. Their processing to timber is about 70 to $75 \%$, which represents more than 3.5 mil. $\mathrm{m}^{3}$ of timber with high moisture content. It is recommended that all timber should be dried to a level of moisture content, at least $20 \%$ or less depending on its final use.

Artificial drying of timber is one of the major components of heat consumption in the wood-processing industry. It is generally known as a high energy ratio, i.e. up to $60-70 \%$ of the total energy used for the production of timber is consumed mainly for timber drying. Therefore, in order to be able to indicate and determine ways on how to improve operation efficiency, decrease overall costs of drying, achieve satisfactory quality of dried timber, and at the same time implement the above technology in an environmental-friendly way, it is necessary to specify both in a complex way and in detail the currently highly topical process of timberdrying. One of the possibilities of saving fossil fuels used for timber drying is also the use of solar energy, as an alternative energy source for solar-based timber-drying kilns. In economical and energy/policy sense, the sun energy due to its availability and flexibility in terms of usage of new technology seems to be very important and at the same time in our environment one of the most promising renewable energy sources. Energy gained from sun radiation increases neither the concentration of the carbon dioxide nor other "dangerous" gases in the air, hence it does not worsen the "greenhouse effect".

\section{Climate conditions}

The SR is a mountainous country. All the Slovak mountains belong to the Carpathian system. According to the global climatological classification, the SR belongs to the mild climate zone. Regular rotations of four seasons and variable weather throughout the year are typical for this country. Compared to the Czech Republic and Austria which lie more to the west, the climate in the SR has more continental features. The average January temperature ranges from $-1^{\circ} \mathrm{C}$ in the Danube lowlands to $-12{ }^{\circ} \mathrm{C}$ on the top of the Tatra Mountains. Average temperatures in July exceed $20{ }^{\circ} \mathrm{C}$ in the Slovak lowlands, while at the elevations of $1000 \mathrm{~m}$ a.s.l. they reach about $14{ }^{\circ} \mathrm{C}$. The southern SR receives about 2,000 hours of bright sunshine each year, while the north-west of the country receives only 1,600 hours. Average annual precipitation for the whole territory of the SR is $743 \mathrm{~mm}$. Snow cover is not stable, and

\footnotetext{
* Jozef Víglaský ${ }^{1}$, Nad’a Langová ${ }^{1}$, Peter Horbaj ${ }^{2}$

${ }^{1}$ Faculty of Environmental and Manufacturing Technology, Technical University in Zvolen, T. G. Masaryka 2117/24, 96053 Zvolen,

Slovak Republic, E-mail: viglasky@vsld.tuzvo.sk, langova@vsld.tuzvo.sk

${ }^{2}$ Mechanical Engineering Faculty, Technical University in Košice, Vysokoškolská 4, 04200 Košice, Slovak Republic, E-mail: peter.horbaj@tuke.sk
} 
winters in the lower altitudes are usually without permanent snow covering.

\section{Objectives}

In the various studies on solar heat drying published during the last decades (e.g. Steinmann-Vermaas 1990, Steinmann 1992), it has been shown that the operating conditions are influenced by numerous factors, such as location, climate, wood species, dimensions and type of kiln used. Therefore it is not possible to generalise, and each situation, location and particular application must be studied in detail.

The research was focused basically on the design of the kilns, and the aspects of regulation and control have been studied with regard to the fact that the period of solar radiation is determined by natural laws, i.e. its range varies greatly during the day and even season, therefore it is necessary to provide, apart from the solar energy, the heat supply from another energy source in a continual drying kiln to optimise the co-operation of two heat energy sources.

\section{The Solar Timber Drying Kiln}

The prototype solar kiln placed in the furniture factory is shown schematically of its solar air collector in Figure 1. The test runs described in this contribution were carried out in the town of Skalica, $48^{\circ} 51^{\prime}$ Northern latitude, $17^{\circ} 14^{\prime}$ Eastern meridian, $178 \mathrm{~m}$ a.s.l. and with approximately 2,100 hours of sunshine per year. The collector is external to the drying chamber so that the collector area and orientation are not limited by the geometry of the kiln.

\section{Construction details of the kiln}

\section{Structure of the kiln}

We used a commercial drier type KWB 111 that was slightly accommodated to be joined to a solar air collector. The singlerow low-capacity kiln has a $7 \mathrm{~m}^{3}$ sawn timber volume. The timber stack measures are as follows: the width of $1500 \mathrm{~mm}$, the height of $1750 \mathrm{~mm}$, and the length of $6000 \mathrm{~mm}$. The kiln is designed to dry coniferous and broad-leaved sawn timber or bulks at $100{ }^{\circ} \mathrm{C}$ max. drying temperature.

Solar air collector

As specific conditions occur during the drying process of sawn timber using solar energy by means of solar air collectors, the first part of our investigation was aimed at a comprehensive theoretical analysis followed by an experimental analysis of the solar air collector work from the viewpoint of optimising its parameters for application in the chamber kiln heating system. An experimental solar system was designed at the Technical University in Zvolen to test and investigate representative characteristics of solar air collectors [1].

The heat for the kiln is supplied by $20 \mathrm{~m}^{2}$ external air heating, solar collector facing south and inclined at $45^{\circ}$ to the horizontal (latitude of the solar kiln site $17^{\circ} 14^{\prime}$ ) for optimum year round performance. One centrifugal blower sucks heated air from the collector into the drying chamber, through an insulated duct. Heat output of the solar air collector (see Figure 2).

Air was circulated over the collector and through the load at $3 \mathrm{~m} \cdot \mathrm{s}^{-1}$. Vents and a spray system were used to control the relative humidity in the kiln.

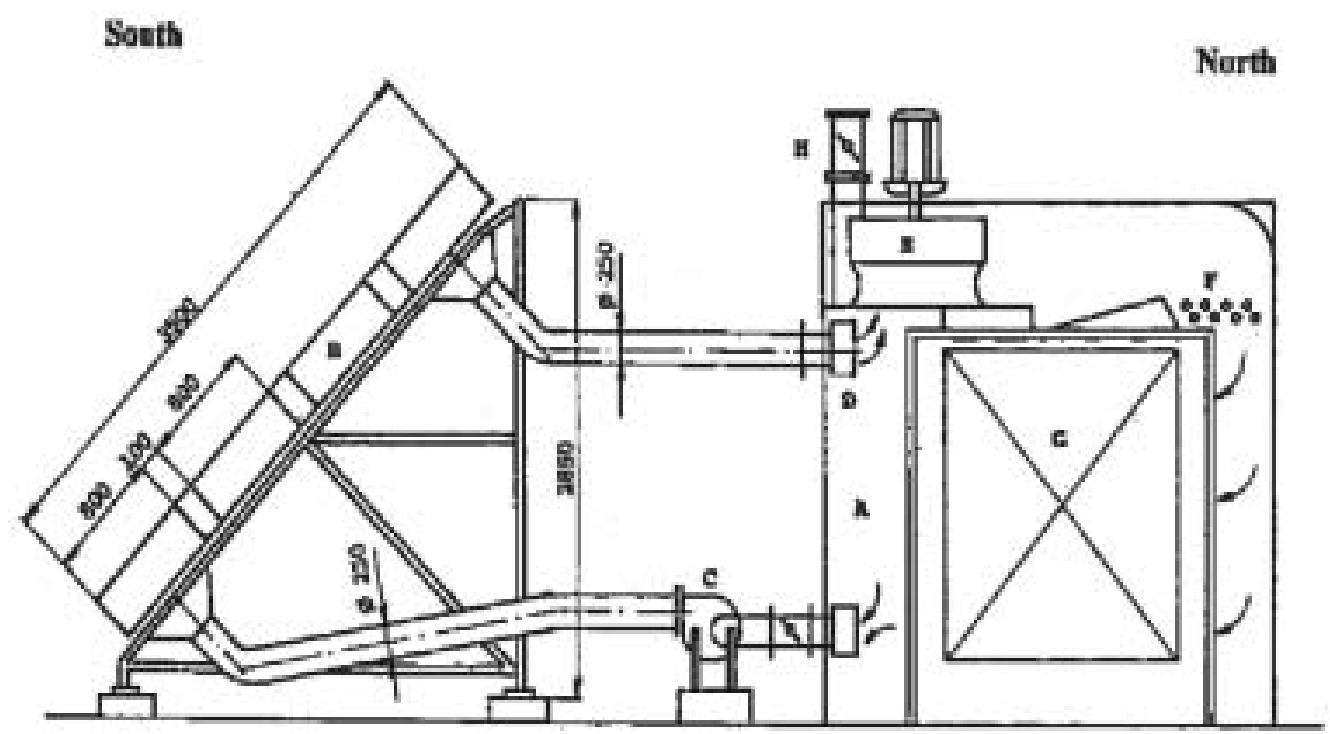

Fig. 1 The Solar Timber Drying Kiln

The Solar Kiln Scheme. (A) Drying chamber; (B) Solar collector; (C) External blower to induce air flow through the collector; (D) Hot air discharge to internal fans; (E) Internal fans; ( $F)$ Heaters; $(G)$ Wood stack; $(H)$ Aeration stacks. 


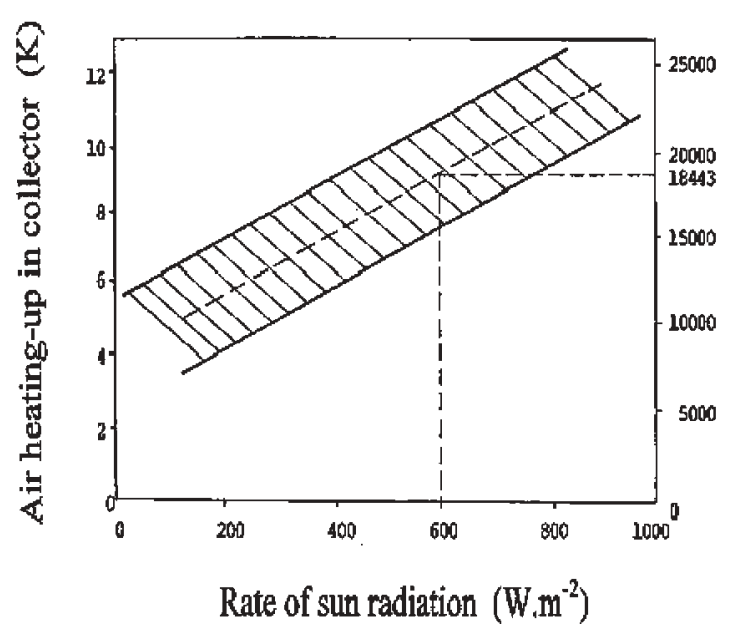

Fig. 2 Heat Output of Solar Air Collector used for the Solar Timber Drying Kiln

The solar kiln was controlled up to now by a semi-automatic control system consisting of: a differential temperature controller, a maximum relative humidity controller, a minimum relative humidity controller, a humidistat, a thermostat, and a timer. The whole control system can be manually checked by switches, but a sensitive and effective equilibrium moisture content (EMC) control system based on control logic is required for performance in the solar kiln to protect wood quality as well as to maintain optimum drying rate and also to prevent energy loss through useless venting.

The temperature and relative humidity of the air inside and outside the kiln, the mass of the kiln load, the status of the venting system (open/closed), the moisture content of the kiln load, the time of the day, and the solar radiation were recorded at $15 \mathrm{~min}$. intervals.

The ratio of collector area to loading capacity is $2.86 \mathrm{~m}^{2} \cdot \mathrm{m}^{-3}$, which agree with recommendation - the optimum collector ratio in respect to drying rate lies in the range between 2 and $7 \mathrm{~m}^{2} \cdot \mathrm{m}^{-3}$ run [5].

\section{Experimental Part}

\section{Solar drying}

Test drying runs were carried out using wood species - Pine Monterey [Pinus radiata D. Den.], thickness dimension of $24 \mathrm{~mm}$ to assess the kiln by the following criteria:

- Drying time.

- Final wood moisture content.

- Drying quality.

- Supplemental energy.

- Temperature and relative humidity conditions in- and outside the kiln.

- Efficiency of the drying process.

\section{Solar radiation.}

The solar radiation recorded during runs was done by the radiation pyrometer HEMI (Solar Sensor 118 SN-8580, Swiss Instrument - HEMI-Messgeräte, $100 \mathrm{~V}=1000 \mathrm{~W} \cdot \mathrm{m}^{-2}$ ).

Furthermore, the average initial moisture content of the sawn timber to be solar dried was $60 \%$ in the evaluated run. The species dried was Pine radiata, sawn in planks measuring $3,000 \mathrm{~mm}$ in length, $100 \mathrm{~mm}$ in width and $24 \mathrm{~mm}$ in thickness. In the evaluated run the $7.0 \mathrm{~m}^{3}$ kiln load was piled using $18 \mathrm{~mm}$ square piling sticks and placing the boards edge to edge in each layer. Six kiln samples ( 3 quarter-sawn, and 3 flat-sawn) were built into the stack in order to study/double check the progress of drying.

During runs, the kiln was operated and supervised for 8 hours per day by a skilled operator. The operator's main task was to maintain the drying gradient as near as possible to the target-drying gradient through the adjustment of the humidistat and the maximum and minimum relative humidity controllers. The rest of the job was done by the semi-automatic kiln control system mentioned above. The drying process during the evaluated run was carried out under the control of the automatic system, without any intervention.

A test for the existence and intensity of casehardening stresses was made immediately prior to the conclusion of both runs. Six prongs were cut $200 \mathrm{~mm}$ from one end of sample boards from each pile. The prongs were made by cutting out the centre portion to within $25 \mathrm{~mm}$ of one end of $13 \mathrm{~mm}$ thick cross-sections. The intensity of casehardening was assessed after allowing the prongs to dry indoors for 8 hours.

After 80-hours or 5-day solar drying period the average moisture content of sawn timber found to be $20 \%$ in representative evaluated run.

During the run the drying chamber temperature was varying in range of $30-40{ }^{\circ} \mathrm{C}$, but the drying condition expressed by the equilibrium moisture content (EMC) was constant, in the mean average of $10 \%$.

\section{Air-drying}

Simultaneously with the solar drying and using the same species and sizes, air-drying test runs were carried out. The drying quality was evaluated, and both drying time and final wood MC were recorded. It was then possible to calculate the drying rates of both methods and compare them.

\section{Results and discussion}

The variables were selected according to a preliminary plan, which would allow conclusions about the two different drying methods, by comparing the results. The variables considered were: - Species of wood. 
- Thickness.

- Time of year.

- Initial and final moisture content.

Comparing drying time of runs (same thickness - e.g. $24 \mathrm{~mm}$, same species - e.g. Pine, solar kiln and air drying), the conclusion is that solar drying is 6 times faster ( 80 hours) than air-drying (480-510 hours).

With regard to the species, comparing the runs (same thickness, different species) leads to the conclusion that although solar drying of hardwood is slower and more expensive than air drying, it is more profitable than for softwoods (conifers).

Comparing the results of runs (same species, different thickness), the conclusion is that solar drying is more profitable for thicker samples.

Since solar drying is only faster than air-drying below 70 to $80 \%$ wood MC, the initial moisture content is of importance. The influence of the final moisture content is particularly marked below $20 \%$, as the solar method becomes more profitable the lower the desired final wood moisture is.

With regard to cracks, splits, honeycombing and final moisture content, the quality of solar dried timber is better than for air-dried stock. The quality is comparable or even superior to that obtained by the conventional kiln drying method [8, 9, 10, 11, 12, 13].

As expected, the efficiency of solar drying improves with an increase of the average external temperature and is more effective during the first stage of the drying process than in the second stage when the wood MC is already below $40 \%$.

With regard to economics it must be pointed out that the supplemental energy consumed $(\mathrm{kWh})$ per $\mathrm{kg}$ of evaporated water is only approx. one-tenth to the amount used in a conventional kiln.

As the efficiency of the tested solar timber-drying kiln depends strongly on the environmental conditions and mainly on the intensity of the solar radiation collected, the results are only transferable directly to locations of similar latitude.

\section{Solar timber drying kiln control}

In a solar kiln, the maximum temperatures are approximately $50{ }^{\circ} \mathrm{C}$, which lasts only for a very short period of time each day, and is only achieved when the wood is partially dry and can endure these temperatures. Temperature control is not necessary in solar wood drying kilns and, therefore, only the relative humidity of the kiln air has to be controlled according to the given drying schedule.

The relative humidity inside the solar kiln should be computer controlled in such a way that venting will take place if it rose above the target value as given by the drying schedule and if, at the same time, the absolute humidity of the outside air is less than the absolute humidity of the air inside the kiln. Unless both conditions are not satisfied simultaneously, venting will not occur. This will be to prevent air with too high moisture content from entering the kiln. With this control, venting will be optimised, preventing loss of energy $[6,7]$.

An efficient solar kiln control system giving the best possible quantitative and qualitative results for the final product should ensure that the drying operation is always modulated to match a current timber condition at any moment of a drying period. Such a system should guarantee the maximisation of energy input to the drying chamber and the minimisation of energy losses through ventilation and useless air circulation.

\section{Additional heating system}

An idea of additional heating system to speed up drying and to support the drying process during periods of low solar radiation as well as to increase the average night temperature is recommended to be take into account [2].

With regard to the fact that the period of solar radiation is determined by natural laws, i.e. its range varies greatly during the day and even season it is necessary to provide, apart from the solar energy, the heat supply from another energy source in a continual drying kiln.

The problem of an additional heating system used in the solar kiln to improve its efficiency was successfully solved at the Technical University in Zvolen. Several control aspects were investigated $[2,3,4]$.

This problem has been solved in an original way of regulating the heating system with a binary source of heat. The above regulation makes it possible to optimise the co-operation of two heat energy sources in the kiln in such a way that it maximises utilisation of solar energy and minimises the heat consumption from conventional energy source, e.g. steam or hot water.

A systematic approach is required in this field to generate results which would serve as guidelines in the design, control and use of a solar kiln of a new generation.

\section{Conclusions}

Many rural and small urban localities are strongly economically dependent on wood processing plants. These small processing plants (as well as the large ones) are beginning to experience difficulties in energy supplies and costs. Because of high economics, not all mills are able to burn mill residues for energy (i.e. excessive capital costs), and must rely on fossil fuels for energy.

The application of solar energy to wood processing holds exciting promise of energy savings. To illustrate this, consider timber 
drying - one of the major energy users in wood processing. Most of this energy is fossil fuel based.

\section{Why is solar energy utilisation so potentially exciting?}

First, wood processing requires temperatures between $30{ }^{\circ} \mathrm{C}$ and $80^{\circ} \mathrm{C}$ and requires energy at a fairly even demand. Therefore, extra large solar collecting surfaces are not required.

Second, a great deal of experimentation has been done in solar energy technology.

A few experimental, small-scale, solar timber-drying kilns have been built in the Slovak Republic as well as in other parts of Europe and the World. Therefore, although designs will continue to improve, workable designs are available today.

This task Application of solar air collector for sawn timber drying and other tasks were researched as part of the main task Utilisation of non-conventional and secondary energy sources for sawn timber drying and kiln which was carried out at SDVU in Bratislava and other co-operating institutions - Vzduchotechnika Nove Mesto nad Vahom, THERMO-SOLAR ZIAR as well as the Technical University in Zvolen.

\section{Acknowledgements}

This research was partly sponsored with grants from the Scientific Grant Agency of Ministry of Education of the Slovak Republic and Slovak Academy of Sciences, under the contract No. 1/2382/05 VEGA; EC Projects: PN 116441-CP-1-2004-1-FR-MINERVA-M, title: BIO-eTRAIN "The Implementation of an e-Learning University for Bioenergy"; Project No: 012429 - BIOPROS "Solutions for the safe application of wastewater and sludge for high efficient biomass production in Short-Rotation-Plantations"; Leonardo da Vinci Project: EnTraCoP - Enhancing the Teaching of Collaborative Planning in Natural Resource Management, the Agreement No.: 2005 FI- 05-B-F-PP-160633. Project "FET-EEU” full title: Future Energy Technologies for Enlarged European Union; Proposal/Contract No.: 510417. The authors are indebted to the mentioned institutions for helping to sponsor this research work.

\section{References}

[1] VÍGLASKÝ, J.: Proposal for an experimental way and installing of an experimental system for testing solar air collectors. (TU in Zvolen, Report no. A02-522-804/1, 1987), 26 p. (in Slovak).

[2] VÍGLASKÝ, J.: R\&D of a highly efficient solar air collector for its application at a low capacity sawn timber kiln. (TU in Zvolen, Report no. A 02-522-804/2, 1988), 66 p. (in Slovak).

[3] VÍGLASKÝ, J.: Technical-economic evaluations of a solar air collector application at a sawn timber kiln. (TU in Zvolen, Report no. 02-522-804/3, 1989), 53 p. (in Slovak).

[4] VÍGLASKÝ, J.: A new energy model of a solar kiln, in Proceedings of the Scientific Seminar on "Zvolen - town of wood science and practice". TU Zvolen, (1993): pp. 365-374 (in Slovak).

[5] STEINMANN, D. E.: The effect of collector area and solar tracking on the performance of a solar lumber drying kiln. In: Proceedings of $3^{\text {rd }}$ IUFRO International Wood Drying Conference. Vienna, Austria. pp. 283-291 (1992).

[6] FRUHAUFOVÁ, I.: Actualization of environmental regionalization SR - work for ArcView. Enviromagazín, 4/2003, ISSN 1335-1877 (In Slovak).

[7] HORBAJ, P., KUŠNÍR, M.: Experience of production of biogas and wood gas for use in a cogeneration unit. In: „Production and purification of fuels from waste and biomass Technical, Environmental and Social Considerations”, European Commission Directorate General Joint Research Centre, Institute for Energy, CLEANWEB Technical Workshop in collaboration with the Technical University of in Košice and BIOMASA Association, Slovakia, 11.-12.10.2004, Košice http://ie.jrc.cec.eu.int/prewin.

[8] MARKOVÁ, I., KLEMENT, I.: Thermal analysis (TG, DTG and DSC) of hornbeam wood after drying. In: Wood Research, Vol. 48, No. 1/2, 2003, pp. 53-61.

[9] MARKOVÁ, I.: Investigation of the drying process of hornbeam wood using thermal analysis methods (TG, DTG and DSC). In: The Proceedings of International Conference "Issues of Hardwood Research and Utilisation in Europe". University of West Hungary, Sopron, September $25-26,2003,8 \mathrm{p}$.

[10] RAJČAN, E., DANIHELOVÁ, A., RUŽINSKÁ, E.: The Influence of Adhesive on Physical and Acustical Characteristics of Wood. In: The Proceedings of the 12th International Symposium „Progresses in production and application of Adhesive in Wood Industry". TU in Zvolen, 1995, pp. 293-297.

[11] RAJČAN, E., DANIHELOVÁ, A., RUŽINSKÁ, E.: The Influence of Adhesive on Physical and Acustical Characteristic of Wood. WOOD, Vol. 50, No. 12, 1995, pp. 236-265.

[12] DANIHELOVÁ, A.: Experimental verification of validity of the funcionality of the modulus of elasticity on moisture content. In: The Proceedings of International Conference ACOUSTICS '96, Zvolen, 1996, pp. 36-40.

[13] DANIHELOVÁ, A.: Influence of some gaseous and liquid substances on physico-acoustical characteristics of spruce wood. Wood Research, Vol. 43, No. 2, 1998, pp. 29-39. 